\title{
Utility of AIRS Retrievals for Climate Studies
}

\author{
Gyula I. Molnar and Joel Susskind \\ GEST/UMBC \& NASA GSFC, Code 613.5, Greenbelt, MD 20771
}

\section{POPULAR SUMMARY}

Satellites provide an ideal platform to study the Earth-atmosphere system on practically all spatial and temporal scales. Thus, one may expect that their rapidly growing datasets could provide crucial insights not only for short-term weather processes/predictions but into ongoing and future climate change processes as well. Though Earth-observing satellites have been around for decades, extracting climatically reliable information from their widely varying datasets faces rather formidable challenges. AIRS/AMSU is a state of the art infrared/microwave sounding system that was launched on the EOS Aqua platform on May 4, 2002, and has been providing operational quality measurements since September 2002. In addition to temperature and atmospheric constituent profiles, outgoing longwave radiation and basic cloud parameters are also derived from the AIRS/AMSU observations.

However, so far the AIRS products have not been rigorously evaluated and/or validated on a large scale. Here we present preliminary assessments of monthly and 8-day mean AIRS "Version 4.0" retrieved products (available to the public through the DAAC at NASA/GSFC) to assess their utility for climate studies. First we present "consistency checks" by evaluating the time series of means, and "anomalies" (relative to the first 4 full years' worth of AIRS "climate statistics") of several climatically important retrieved parameters. Finally, we also present preliminary results regarding interrelationships of some of these geophysical variables, to assess to what extent they are consistent with the known physics of climate variability/change. In particular, we find at least one observed relationship which contradicts current general circulation climate (GCM) model results: the global water vapor climate feedback which is expected to be strongly positive is deduced to be slightly negative (shades of the "Lindzen effect"?). Though the current AIRS climatology covers only $\sim 4.5$ years, it will hopefully extend much further into the future. 


\title{
Utility of AIRS Retrievals for Climate Studies
}

\author{
Gyula I. Molnar and Joel Susskind \\ GEST/UMBC \& NASA GSFC, Code 613.5, Greenbelt, MD 20771
}

\begin{abstract}
Satellites provide an ideal platform to study the Earth-atmosphere system on practically all spatial and temporal scales. Thus, one may expect that their rapidly growing datasets could provide crucial insights not only for short-term weather processes/predictions but into ongoing and future climate change processes as well. Though Earth-observing satellites have been around for decades, extracting climatically reliable information from their widely varying datasets faces rather formidable challenges. AIRS/AMSU is a state of the art infrared/microwave sounding system that was launched on the EOS Aqua platform on May 4, 2002, and has been providing operational quality measurements since September 2002. In addition to temperature and atmospheric constituent profiles, outgoing longwave radiation [OLR] and basic cloud parameters are also derived from the AIRS/AMSU observations. However, so far the AIRS products have not been rigorously evaluated/validated on a large scale. Here we present preliminary assessments of climatically important "Level3" (monthly and 8-day means, $1^{\circ} \times 1^{\circ}$ gridded) AIRS "Version 4.0" retrieved products (available to the public through the DAAC at NASA/GSFC) to assess their utility for climate studies. Though the current AIRS climatology covers only $\sim 4.5$ years, it will hopefully extend much further into the future. First we present "consistency checks" by evaluating the $\sim 4.5$-yr long time series of global and tropical means, as well as gridscale variability and "anomalies" (relative to the first full years worth of AIRS "climate statistics" of several climatically important retrieved parameters). Finally, we also present preliminary results regarding interrelationships of some of these geophysical variables, to assess to what extent they are consistent with the known physics of climate variability/change. In particular, we find at least one observed relationship which contradicts current general circulation climate (GCM) model results: the global water vapor climate feedback which is expected to be strongly positive is deduced to be slightly negative (shades of the "Lindzen effect"?).
\end{abstract}

Keywords: infrared, remote sensing, satellite sounders, cloud parameters, sea surface temperature, surface skin temperature, upper tropospheric humidity, outgoing longwave radiation, satellite-based climatic trends

\section{INTRODUCTION}

Operational meteorological satellites capable of atmospheric sounding have been in polar orbits for nearly three decades. However, comprehensive satellite-based atmospheric parameter climatologies are sill in their infancy. In principle, satellite sounders can provide an ideal platform to retrieve important atmospheric variables simultaneously and even on longer time scales. The TOVS satellites were the first to provide comprehensive atmospheric soundings since 1979 on. For example, Susskind et al. ${ }^{1}$ and Mehta et. al. ${ }^{2}$ have generated OLR and cloud fields using TOVS observations. The AIRS/AMSU operational since Sept. 2002), accomplishes the same tasks with a much higher accuracy (e.g., Susskind et al., $\left.{ }^{3,4}\right)$. It would be very useful for climate change assessments to have the longest possible climatologies, so in case the preliminary AIRS results are encouraging, we can extend the TOVS Path-A-based retrieval results to the future to create an at least three-decade long satellite sounder based climatology. Why satellites sounders are so special? Their main ability to retrieve vertical profiles of atmospheric temperature and humidity may be regarded as having a twice-a-day global coverage of radiosondes, which are perhaps one of the most important atmospheric measurement platforms to understand the physics of the atmosphere. Unfortunately, they have at most only a one-third of global coverage, and a very uneven (spatially) of that. No wonder then that, for example, a good understanding of water vapor (the most important greenhouse gas)-related climate feedbacks is not well established, as the still lingering Lindzen ${ }^{5}$ hypothesis indicates. Reliable, long-term satellite sounder measurements would help make GCMs a much more reliable tool in (at lest) two ways: they could provide input for the necessary parameterizations on one hand, and test/validate the model results on the other. 
The AIRS/AMSU sounding retrieval methodology allows for the retrieval of key atmospheric/surface parameters under partially cloudy conditions. The following bullets highlight an overview of the AIRS/MSU Version 4.0 retrieval methodology in some detail:

- Physically-based system;

- Independent of GCM except for surface pressure;

- Uses cloud cleared radiances to produce solution;

- Basic steps:

1) Microwave product parameters - solution agrees with AMSU-A radiances;

2) Initial cloud clearing using microwave product;

3) AIRS regression guess parameters based on cloud cleared radiances;

4) Update cloud clearing using AIRS regression guess parameters;

5) Sequentially determine surface parameters, temperature, moisture, ozone, $\mathrm{CO}$, and $\mathrm{CH}_{4}$ profiles;

-Apply quality control:

a) Select retrieved state - coupled AIRS/AMSU or AMSU only retrieval parameters;

b) Determine cloud parameters consistent with retrieved state and observed radiances. One set per Field-ofView of effective cloud fraction $\left(A_{\text {eff }}\right)$ for up to two cloud layers, as well as cloud top pressure $\left(C_{t p}\right)$ for up to two cloud layers;

c) Compute all-sky OLR and clear-sky OLR from all parameters via radiative transfer. Note that in Version 4.0 the all-sky OLR gridded product calculation had an error, so in the followings we use only the clear-sky OLR product.

\section{METHODOLOGY}

In order to assess the reasonableness and compatibility of DAAC AIRS Version 4.0 Level 3 products, we have obtained $1^{\circ} \times 1^{\circ}$ gridded monthly mean as well as 8-day average data, covering the longest time period available at this time, i. e., from Sept. 2002 till the beginning of March 2007. The latter dataset was obtained to assess (in terms of Hovmoller diagrams) shorter-scale phenomena and to see what we are missing (if anything important) when addressing climate variability based on the "standard" monthly mean retrieval products. These data are available through the (http://disc.gsfc.nasa.gov/data/datapool/AIRS/index.html) WEB-site of the DAAC at NASA/GSFC.

Our main aim here is to assess eventual utility of AIRS data for climate research, and this requires compatibility with variability of other long term data sets. A preliminary inter-comparison of interannual/intraseasonal variability was presented in last year's volume of this conference ${ }^{6}$. Here we focus on the internal consistency of the 4.5 year long series of "climatic anomalies", relative to the mean seasonal "climates" obtained from the averaging of the first four years of each respective "AIRS month". All DAAC Version 4.0 monthly mean fields have been spatially interpolated to include missing data grid points, whilst elevated terrain is excluded at the appropriate pressure levels. After the AIRS 4 year $1^{\circ} \times 1^{\circ}$ monthly mean "climatologies" were generated, we've computed the monthly mean anomalies as area weighted (when "areas" were larger than the $1^{\circ} \times 1^{\circ}$ grid) differences from the area weighted monthly climatologies. For computing 8-day average anomalies, we've linearly interpolated the monthly mean climatologies to the midpoints of the time-of-year of the 8-day products. Considering the relatively short length of the AIRS dataset, regional anomalies/trends, which tend to be always larger than global anomalies/trends, are expected to be less affected by possible instrumental drifts, for example. Thus, besides creating the time series of global, tropical and regional anomalies, we've computed linear trends fitted to the anomaly time series of each grid-point also.

Next, interrelationships among the various anomaly products are addressed and evaluated for consistency with principles of atmospheric physics. Of course, we have to keep in mind that findings for a 4.5 year period may not be significant to draw authorative climate inferences.

\section{RESULTS}


Before presenting our "AIRS climate anomaly/trend" assessments, on Fig. 1 we illustrate the AIRS

"climatology" of surface skin temperature for the four representative months of the seasons:

\section{Full Years Based "Climatological" AIRS Surface Skin Temperature Means}
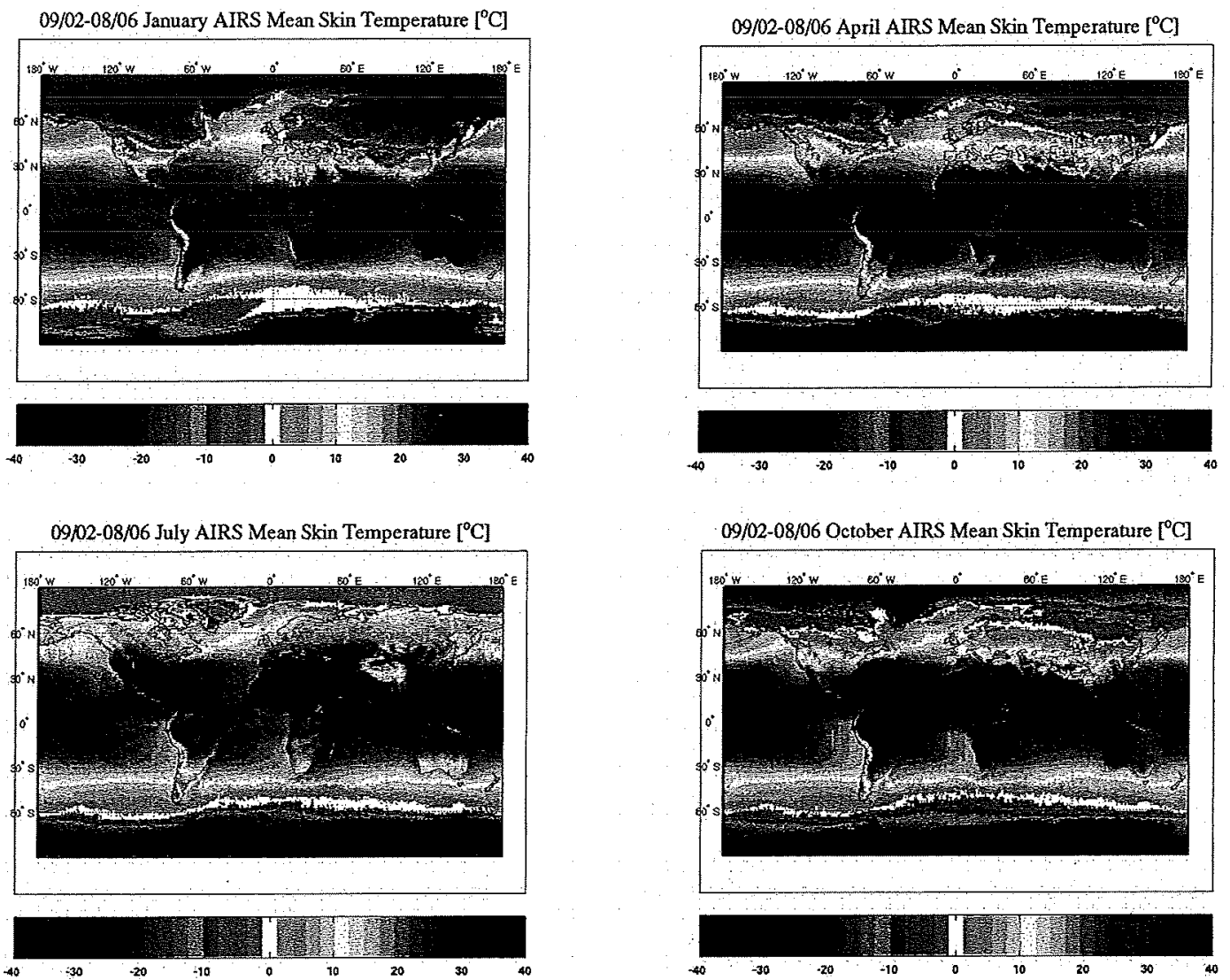

Figure 1

The effect of the yearly march of the solar insolation is obvious.

On Fig. 2 we show four 8-day average maps of the surface skin temperature anomalies, selected from the last 4 months of the. Version 4.0 data. Surface skin temperature is a close proxy of sea surface temperature (SST) over oceans and its anomalies were computed relative to the (so far) 4-yr long AIRS surface skin temperature monthly mean "climatology". It is apparent that the El Niño conditions are turning towards La Niña, by the time shown on the last panel. Indeed, operational SST analyses indicate that a La Niña cycle has started in February, 2007. Fig. 3 compares the NOAA vs. the AIRS anomaly for the beginning of March 2007 for the same map-projection. The NOAA operational SST anomaly figures were taken from the http://www.osdpd.noaa.gov/PSB/EPS/SST/climo.html WEB-site. NOAA/NESDIS has been producing SSTs from satellite data since 1972. Monitoring of SST from earth-orbiting infrared radiometers has had a wide impact on oceanographic science. Beginning in mid-1996, a new satellite-only climatology (for 1984-1993) became available and made it possible to generate more accurate SST anomaly products from the operational $50-\mathrm{km}$ daily SST field. The NOAA/NESDIS operational SSTs are provided twice a week in near real-time and use both day and night retrievals. Since the satellite-only SST monthly mean climatology is derived only from nighttime SST observations to eliminate the diurnal variation caused by diurnal solar heating at the sea surface (primarily at the "skin" interface, 10-20 $\mu \mathrm{m}$ ), only nighttime SST analyses are used to ensure consistency between the satellite SST observations and the climatology. The original satellite-only SST monthly mean climatology data is at $36 \mathrm{~km}$ resolution and was derived from the Multi-Channel SSTs (MCSSTs, see McCain 
et. $a l^{7}$, for example) reprocessed by the Rosenstiel School of Marine and Atmospheric Science (RSMAS) of the University of Miami.

11/11/06 AIRS [8-day Mean] Skin Temperature "Anomaly" [ $\left.{ }^{\circ} \mathrm{C}\right]$
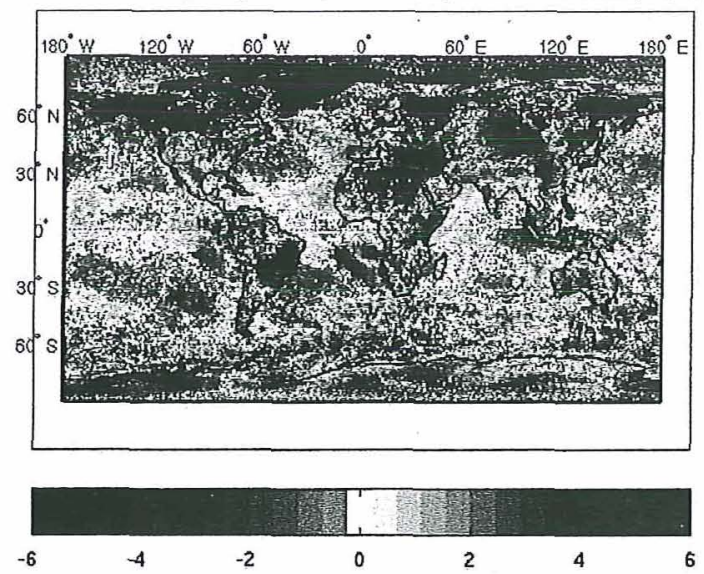

01/14/07 AIRS [8-day Mean] Skin Temperature "Anomaly" [ ${ }^{0} \mathrm{C}$ ]
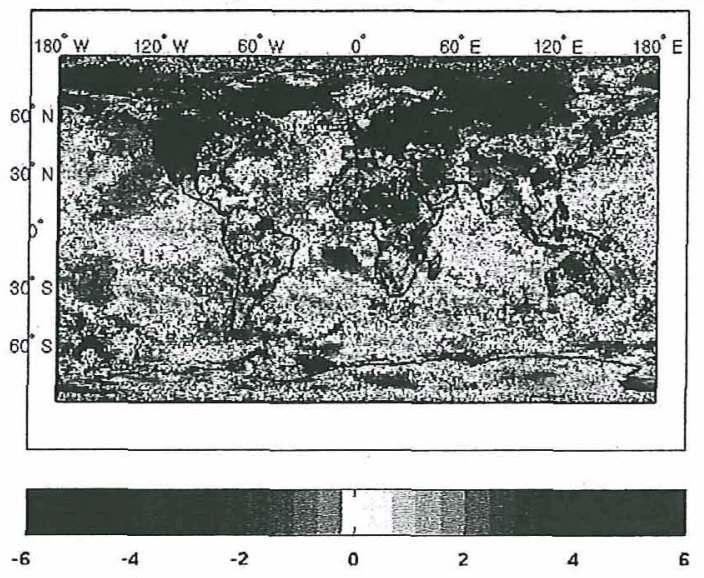

12/13/06 AIRS [8-day Mean] Skin Temperature "Anomaly" [ $\left.{ }^{\circ} \mathrm{C}\right]$
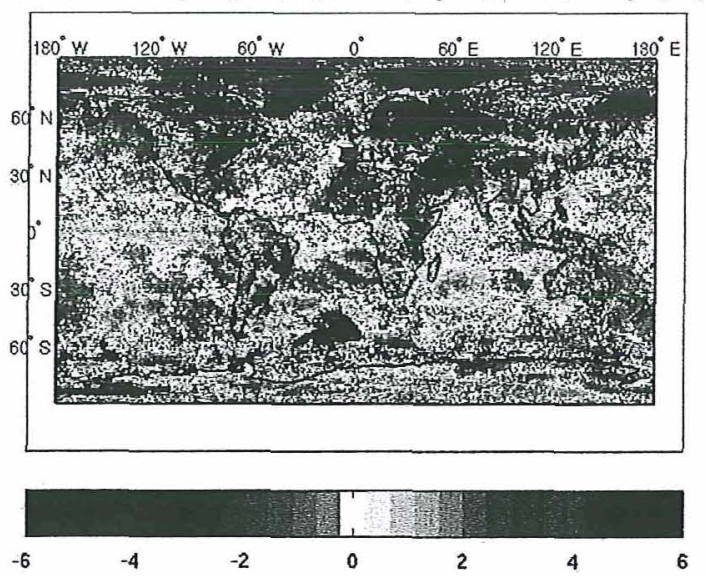

03/02/07 AIRS [8-day Mean] Skin Temperature "Anomaly" [ $\left.{ }^{\circ} \mathrm{C}\right]$
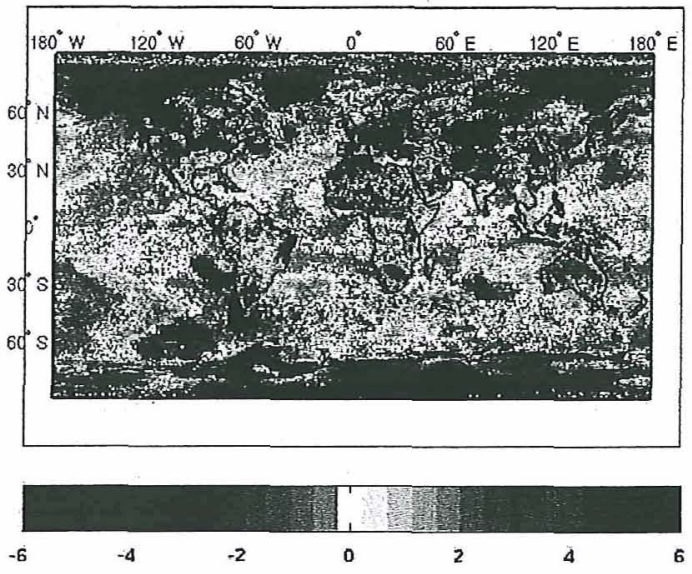

Figure 2
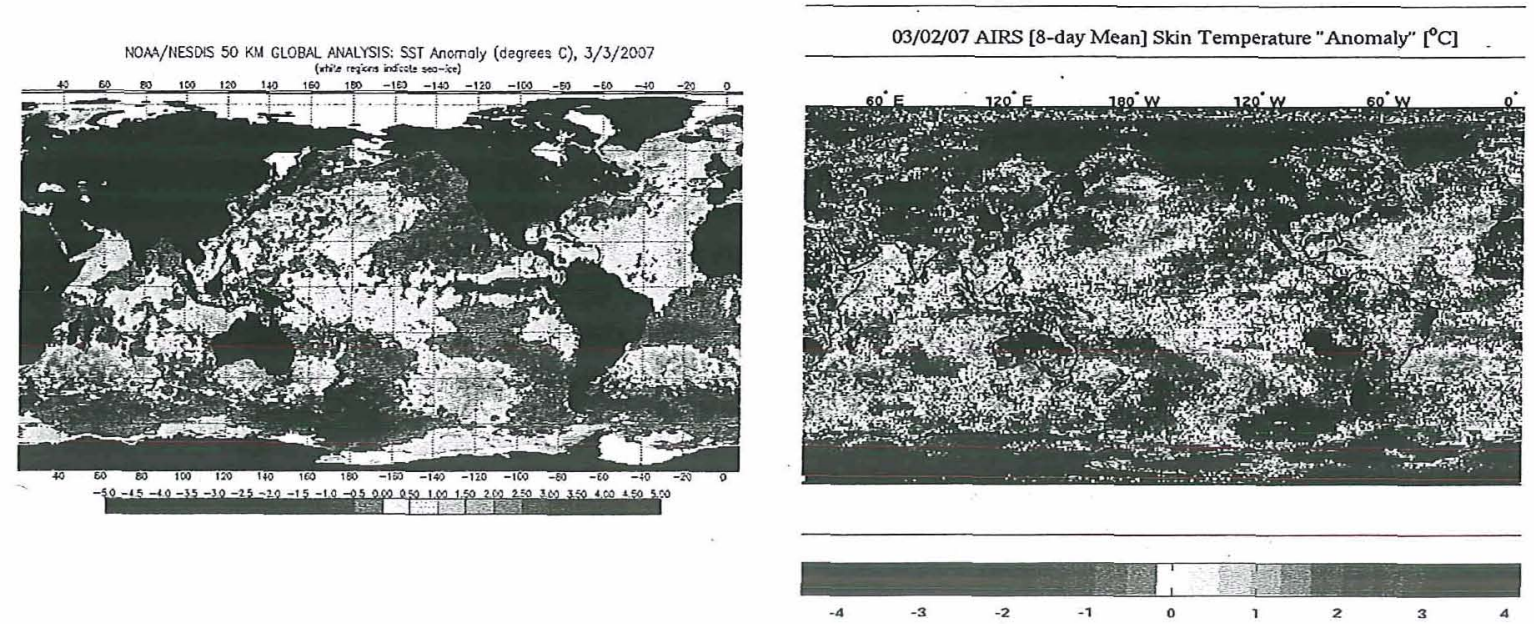

Figure 3 
This climatology is based on nighttime observations from 1984-1993, with SST observations from the years 1991 and 1992 omitted due to aerosol contamination from the eruption of Mt. Pinatubo. In-situ SSTs from drifting and moored buoys are used to remove any biases, and statistics are compiled with time. The monthly
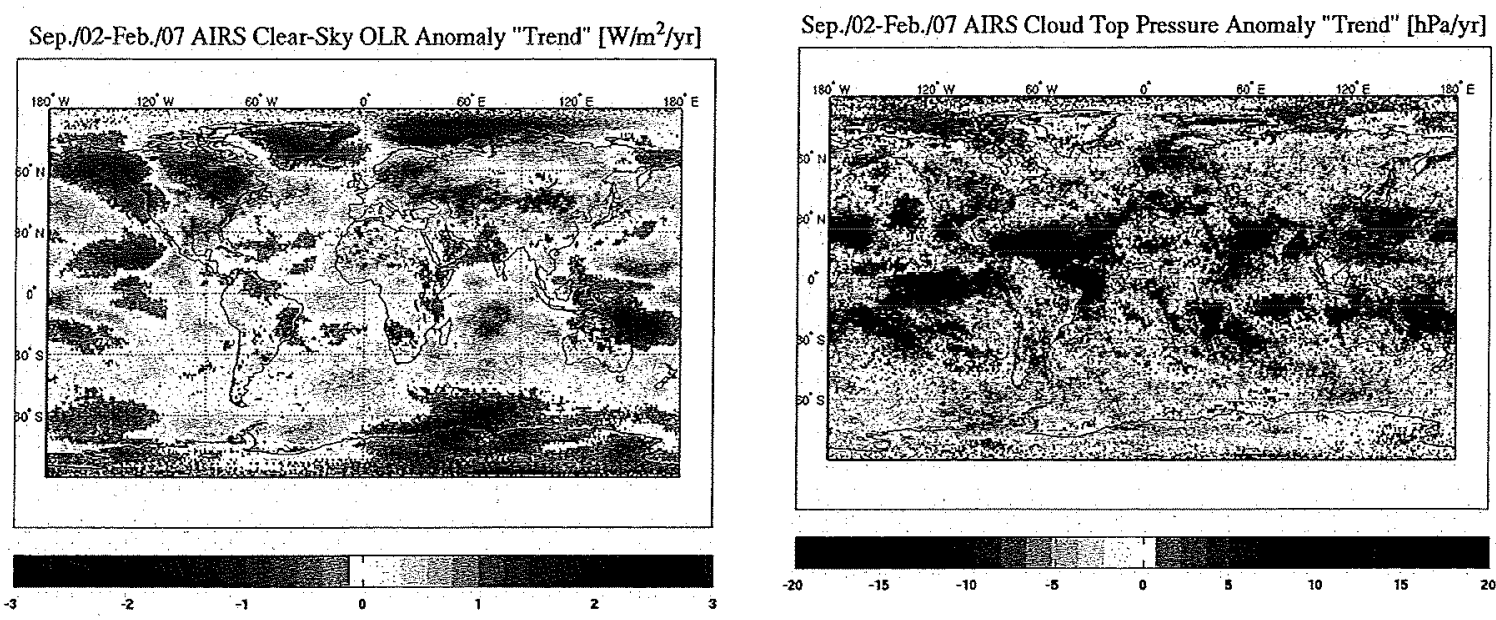

Sep./02-Feb./07 AIRS $500 \mathrm{hPa}$ Temperature Anomaly "Trend" [ $\left.{ }^{\circ} \mathrm{C} / \mathrm{yr}\right]$
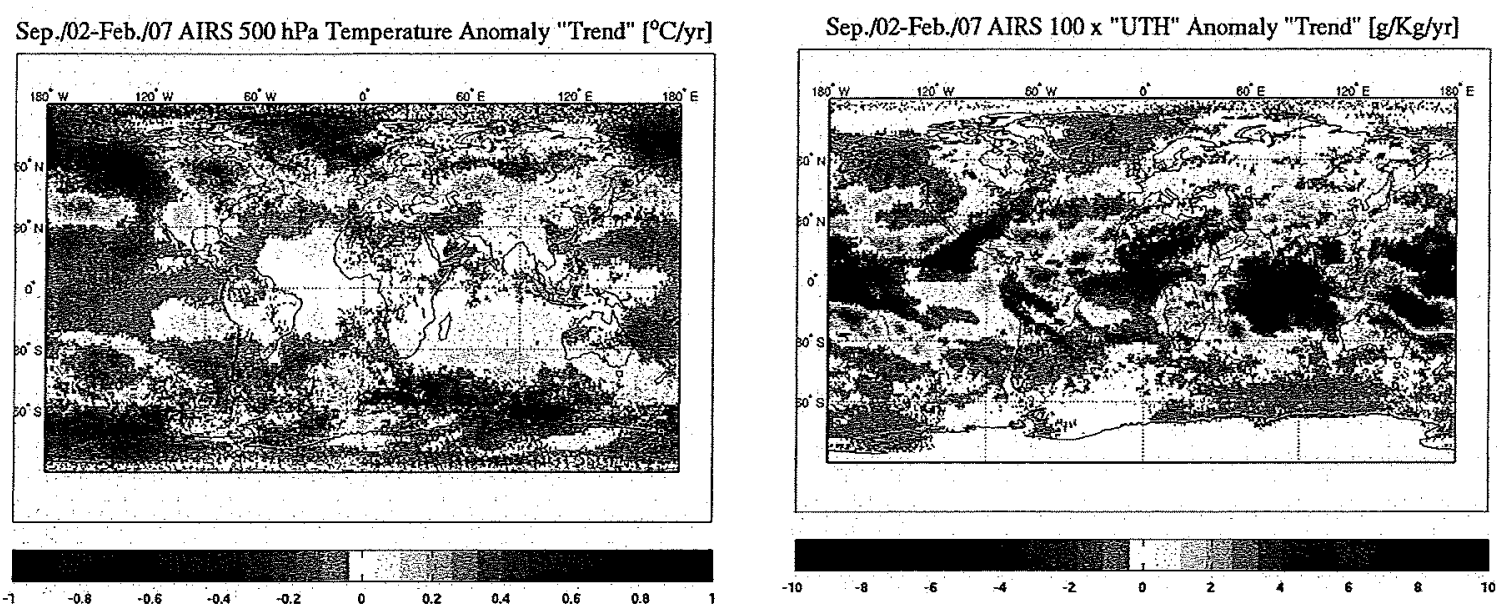

Sep./02-Feb./07 AIRS Effective Cloud Fraction Anomaly "Trend" [\%/yr]
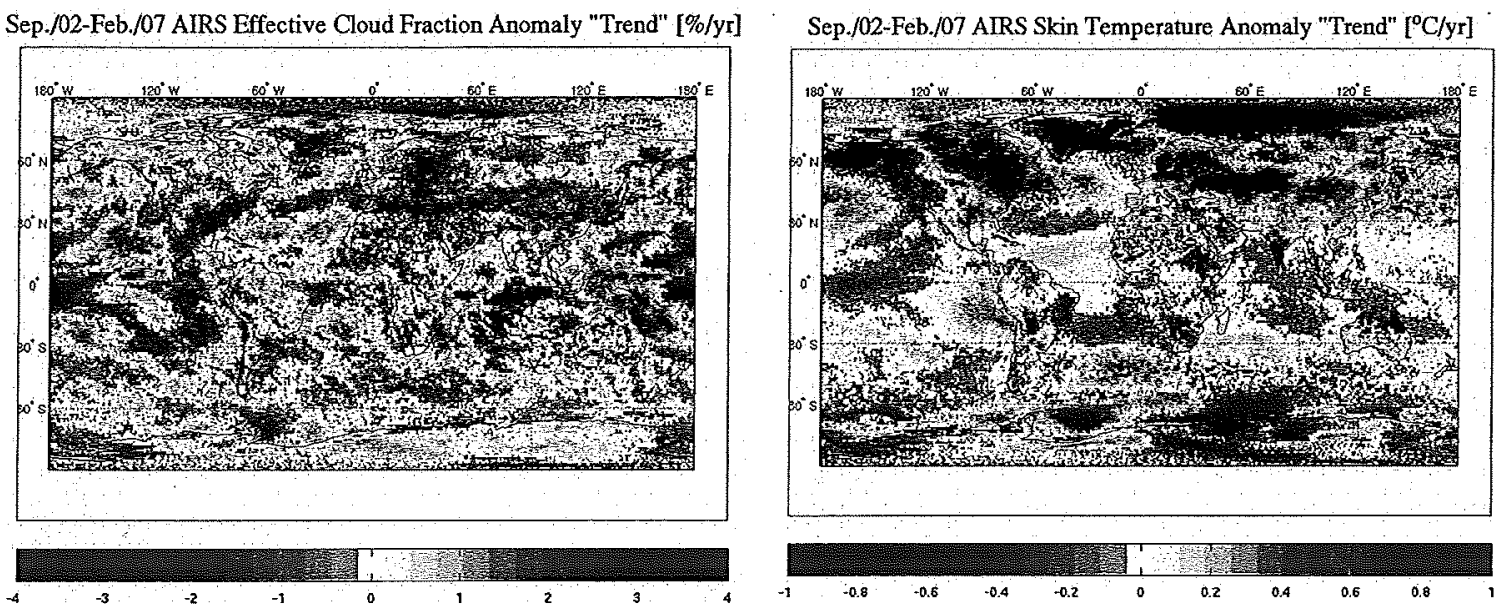

Figure 4 
mean climatology data is then interpolated to $50 \mathrm{~km}$ resolution to match the operational SST field. To obtain the SST climatology for a specific date, just like we are doing for the AIRS climatology, linear interpolation is applied on the two SST monthly mean climatology files that are closest to that date. Despite based on different type of satellite instruments, twice weekly vs. 8-day averages and different climatological 'baselines', the anomaly patterns are reassuringly similar. The only major discrepancy can be seen over the (persistently) marine stratus cloud covered region off the coast of Chile, where the AIRS Version 4.0 retrievals are less reliable due to the broken nature (from the $50 \mathrm{~km}$ AIRS footprint point-of-view) of these type of clouds.

Next we address the detectability of regional trends for several key climatic variables: Fig. 4 shows the gridpoint by gridpoint anomaly trends for six climate parameters. Note that upper tropospheric humidity or "UTH" means specific humidity between the 500 and $200 \mathrm{hPa}$ layers. Pronounced regional patterns are obvious, indicating some hardship GCMs could face to predict regional patterns climate change in general. Cross-correlations between these trendmaps did not reveal strong physical dependencies, except the strong positive correlation between the skin temperature and clear-sky OLR as well as $500 \mathrm{hPa}$ temperature anomaly trend patterns (see also the regular typeface cross-correlation values in Table I among five of the climate variables presented in these trendmaps).

Fig. 5 shows "trends" of the vertical temperature profile anomalies over the first four years of AIRS observations for the Globe and for the Tropics, defined in this work as the average between $20^{\circ} \mathrm{S}$ and $20^{\circ} \mathrm{N}$. Here, the "final" retrieval product (AIRS/AMSU) and microwave product (AMSU only) are compared with themselves and with each other. The microwave product trends should be unaffected by $\mathrm{CO}_{2}$ changes, therefore these trends are not spurious results of $\mathrm{CO}_{2}$ trends. However, agreement of AIRS/AMSU with "AMSU only" does not mean that the trends are not spurious; All AMSU channels are used in Version 4.0 and the "final" temperature profile "trends" could be influenced by "spurious" AMSU radiance trends. Nevertheless the spatial distribution of "trends" should not be affected.
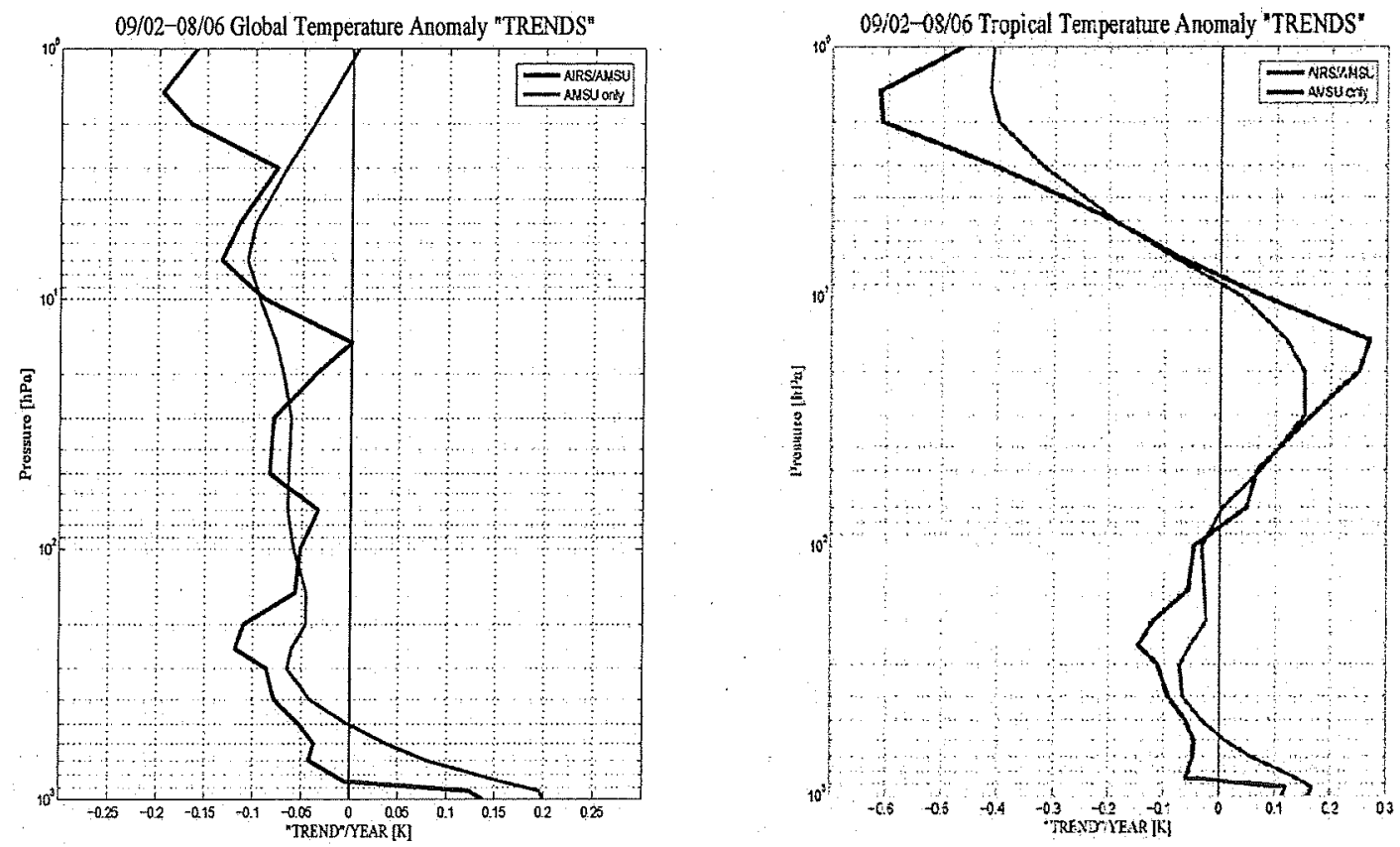

Figure 5

At any rate, the shapes of these temperature anomaly profiles are quite consistent with their expected variations during a greenhouse warming induced climate perturbation. Globally, the GCMs predict surface and lower 
tropospheric warming and mid- and upper-tropospheric as well as stratospheric cooling. In the Tropics, surface, lower tropospheric and upper tropospheric warming as well as mid-tropospheric and stratospheric cooling are expected, and that is what AIRS observes. However, at this point (too short a time-period) the "trend" magnitudes may be overemphasized.

The El Niño/La Niña conditions discussed related to Figs. 2 and 3 prompted us to focus next on the equatorial region: namely the temporal variability of crucial climate parameters at each $l^{\circ}$ longitude averaged latitudinally over the $+/-5^{\circ}$ and the $+/-10^{\circ}$ latitudes. As a function time, these values then constitute the hovmoller diagrams presented in the following figures. First, we've tried to use the monthly temporal resolution level 3 data, but, for example, we could not see (Fig. 6a) the onset of the La Niña on the $\sim 90-180 \mathrm{~W}$ region in February 2007, as indicated by the NOAA SST analyses. Fortunately, 8-day averages are also standard AIRS level 3 products, so we made use of them for the purpose of creating the equatorial hovmoller diagrams. Fig. $6 \mathrm{~b}$ clearly

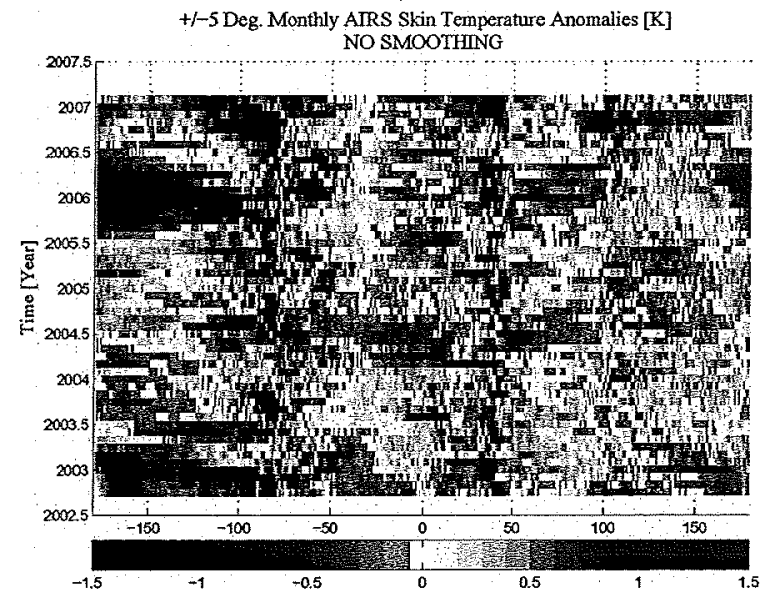

Figure 6a

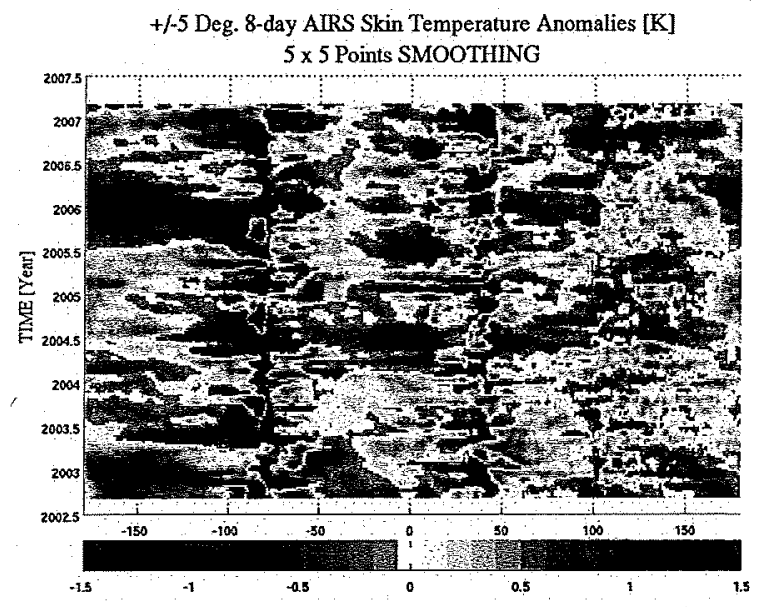

Figure 6b

shows the appearance (upper left corner) of cold SST anomalies in February of this year. Figure 7 consist of an ensemble of additional 5 panels of 8 -day temporal and $+/-5^{\circ}$ latitudinal average based hovmoller plots. Physical relationships among several variables are visible in these plots, in particular between UTH and clear sky OLR, UTH and effective cloud fraction $\left(A_{\text {eff }}\right), A_{\text {eff }}$ and clear sky OLR, as well as skin temperature and cloud top pressure $\left(\mathrm{C}_{\mathrm{tp}}\right)$. These relationships are underlined by the high cross-correlation values shown in bold typeface in Table I, i. e., real physical connections are likely. Though not shown, the $+/-10^{\circ}$ latitudinal average based hovmoller plots show very similar (slightly subdued) patterns and (slightly smaller) cross-correlations.

Table I: Correlations between anomalies of climatic variables for the trendmaps (regular typeface) and for the $+/-5^{\circ}$ latitude belt Hovmoller maps (bold typeface).

\begin{tabular}{cccccc}
\hline & $\mathbf{T}_{\text {skin }}$ & Clear-Sky OLR & "UTH" & $\mathbf{A}_{\text {eff }}$ & $\mathbf{C}_{\mathrm{w}}$ \\
\hline $\mathbf{T}_{\text {skin }}$ & & 0.78 & 0.12 & 0.10 & 0.04 \\
Clear-Sky OLR & $\mathbf{- 0 . 0 4}$ & & -0.23 & -0.11 & 0.05 \\
"UTH" & $\mathbf{0 . 2 1}$ & $\mathbf{- 0 . 8 8}$ & & 0.28 & -0.21 \\
$\mathbf{A}_{\text {eff }}$ & $\mathbf{0 . 0 9}$ & $\mathbf{- 0 . 7 6}$ & $\mathbf{0 . 7 6}$ & & 0.15 \\
\hline $\mathbf{C}_{\text {tp }}$ & $\mathbf{- 0 . 4 7}$ & $\mathbf{0 . 2 1}$ & $\mathbf{- 0 . 2 4}$ & $\mathbf{- 0 . 1 1}$ & \\
\hline
\end{tabular}

Next, we've turned our attention to large-scale anomaly timeseries: global, tropical and regional. For "regions", based on the hovmoller analyses and the ongoing El Niño/La Niña conditions, we've selected "Region\#1" as the $+/-5^{\circ}, 120-180 \mathrm{~W}$ region, and the $50 \%$ larger $+/-5^{\circ}, 90-180 \mathrm{~W}$ region as "Region\#2. Fig 8 a shows the timeseries of the global mean AIRS monthly anomalies. We can see that clouds are definitely extend higher in 

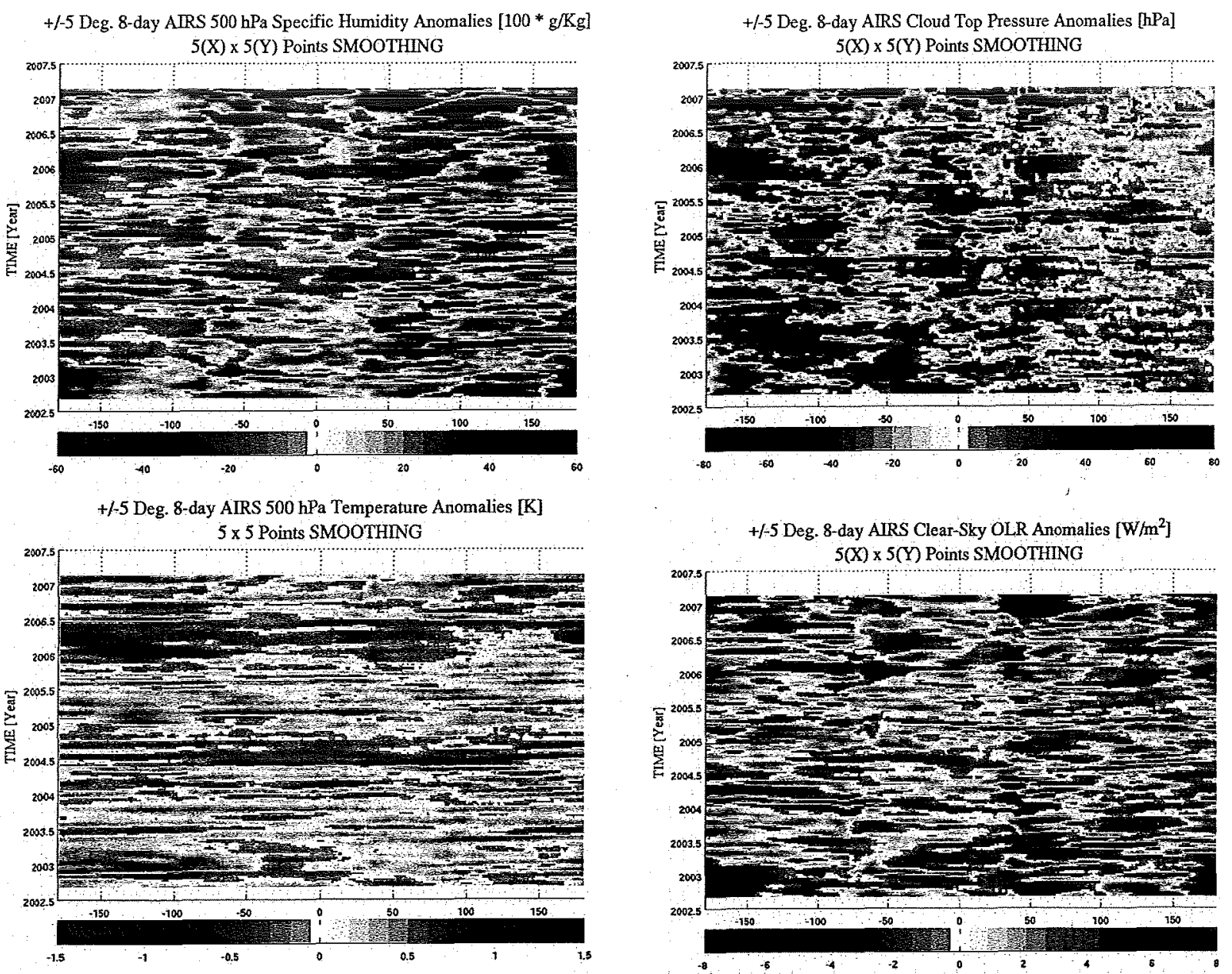

the atmosphere, and surface sky OLR both increase in much of any "trend" is region depicted on Fig 8b, pronounced increase in correlations among these presented in Table $\Pi$, interesting story: Notice the correlation between the temperature and UTH. This been rather high and water vapor climate predicted by GCMs and In fact, the only places we positive correlation are

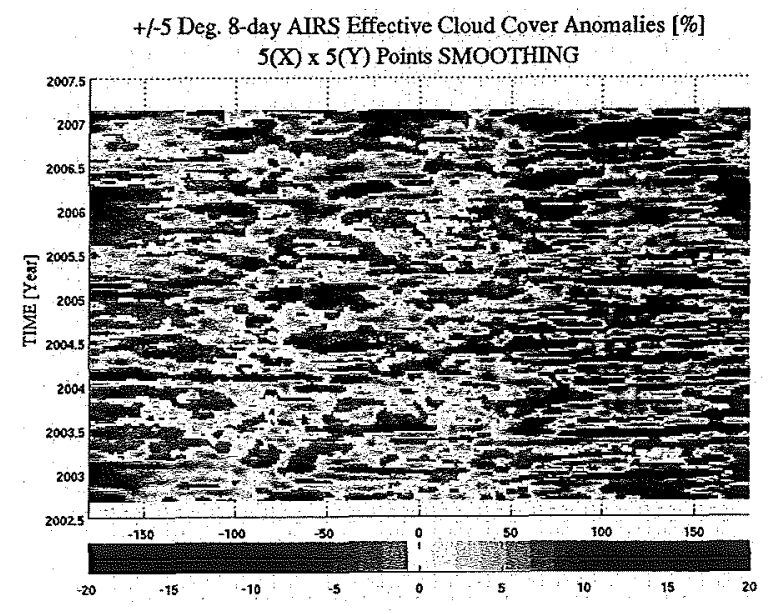

temperature and clearthis 4.5 yr period. Not apparent in the tropical except the still cloud top height. Crossanomaly timeseries, however, tell an week negative global mean surface number should have positive, in case the feedback operated as conventional wisdom. do have a strong "Region\#1" and

Figure 7

"Region\#2", i.e., the warmest equatorial areas (see Table MI). Apparently, leaving the deep tropics, the 
assumed to be all powerful water vapor feedback fades, actually to oblivion in a global sense. This, in turn, leads to less amplified greenhouse warming in the global sense, a kind of in line with Lindzen's old suggestion $^{5}$. In the deep tropics, by the way, all the cross-correlations among the climate variables considered in this study are quite high, as Fig. 8c also attests, showing five of the "Region\#1" anomaly timeseries.

Table II: Correlations between anomaly timeseries of climatic variabies for the Globe (regular typeface) and for the Tropics (bold typeface).

\begin{tabular}{cccccc}
\hline & $\mathbf{T}_{\text {skin }}$ & Clear-Sky OLR & "UTH" & $\mathbf{A}_{\text {eff }}$ & $\mathbf{C}_{\text {to }}$ \\
\hline T $_{\text {skin }}$ & & 0.80 & -0.08 & -0.36 & -0.55 \\
Clear-Sky OLR & $\mathbf{0 . 4 2}$ & & -0.32 & -0.28 & -0.61 \\
"UTH" & $\mathbf{0 . 1 4}$ & $\mathbf{- 0 . 5 3}$ & & 0.25 & 0.44 \\
$\mathbf{A}_{\text {eff }}$ & $\mathbf{- 0 . 3 0}$ & $\mathbf{- 0 . 3 3}$ & $\mathbf{0 . 4 7}$ & & 0.55 \\
\hline Ctp $^{\text {tp }}$ & $\mathbf{0 . 1 8}$ & $\mathbf{- 0 . 1 8}$ & $\mathbf{0 . 3 2}$ & $\mathbf{0 . 3 6}$ & \\
\hline
\end{tabular}

Table III: Correlations between anomaly timeseries of climatic variables for Region\#1 (regular typeface) and for Region\#2 (bold typeface).

\begin{tabular}{cccccc}
\hline & $\mathbf{T}_{\text {skin }}$ & Clear-Sky OLR & "UTH" & $\mathbf{A}_{\text {eff }}$ & $\mathbf{C}_{\text {to }}$ \\
\hline $\mathbf{T}_{\text {skin }}$ & & -0.53 & 0.66 & 0.70 & -0.70 \\
Clear-Sky OLR & $\mathbf{- 0 . 5 3}$ & & -0.93 & -0.84 & 0.64 \\
"UTH" & $\mathbf{0 . 6 9}$ & $\mathbf{- 0 . 9 2}$ & & 0.87 & -0.61 \\
$\mathbf{A}_{\text {eff }}$ & $\mathbf{- 0 . 7 1}$ & $\mathbf{- 0 . 7 8}$ & $\mathbf{0 . 8 5}$ & & -0.57 \\
\hline $\mathbf{C}_{\text {tp }}$ & $\mathbf{- 0 . 6 6}$ & $\mathbf{0 . 5 0}$ & $\mathbf{- 0 . 5 2}$ & $\mathbf{- 0 . 4 0}$ & \\
\hline
\end{tabular}

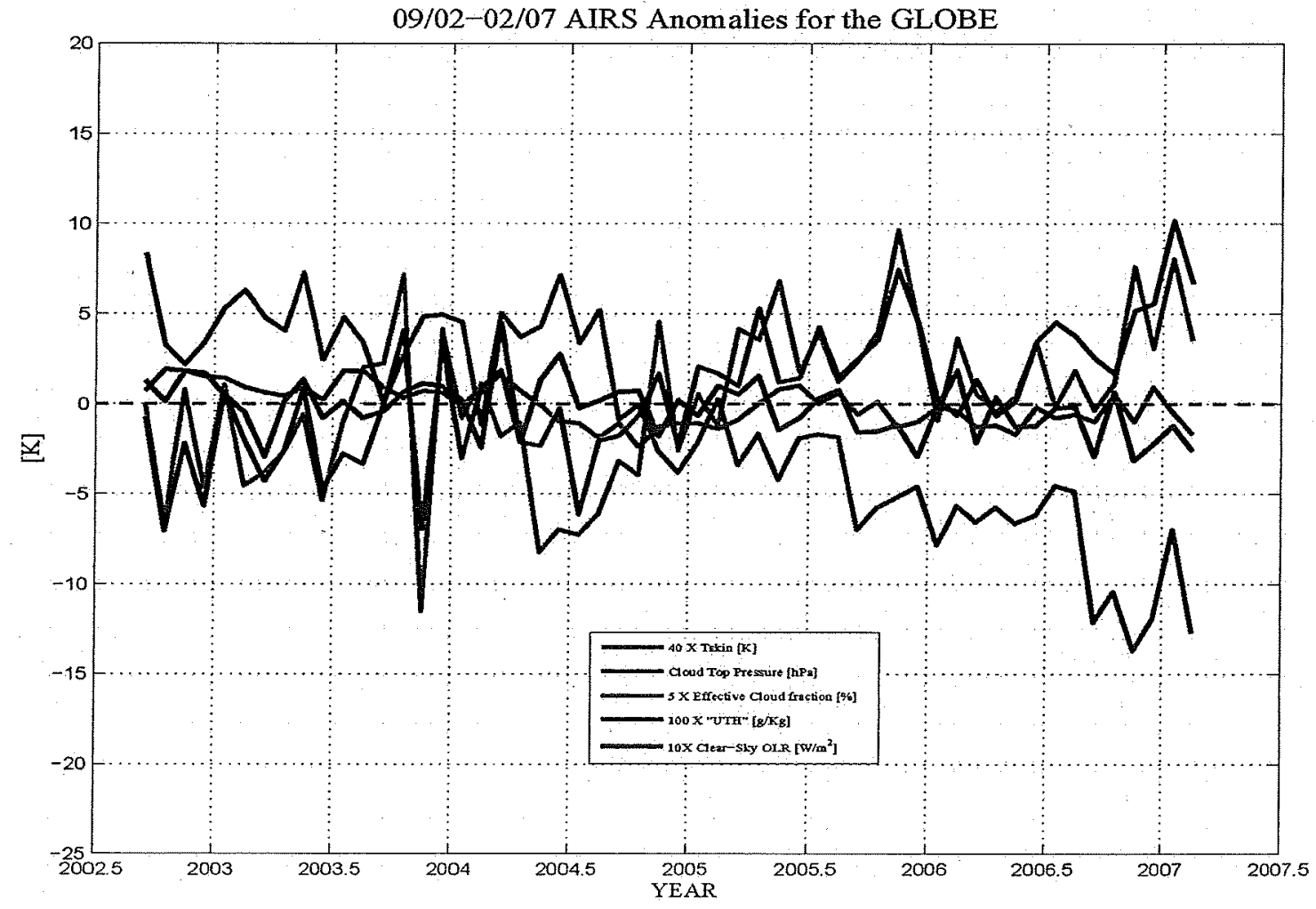

Figure 8a 

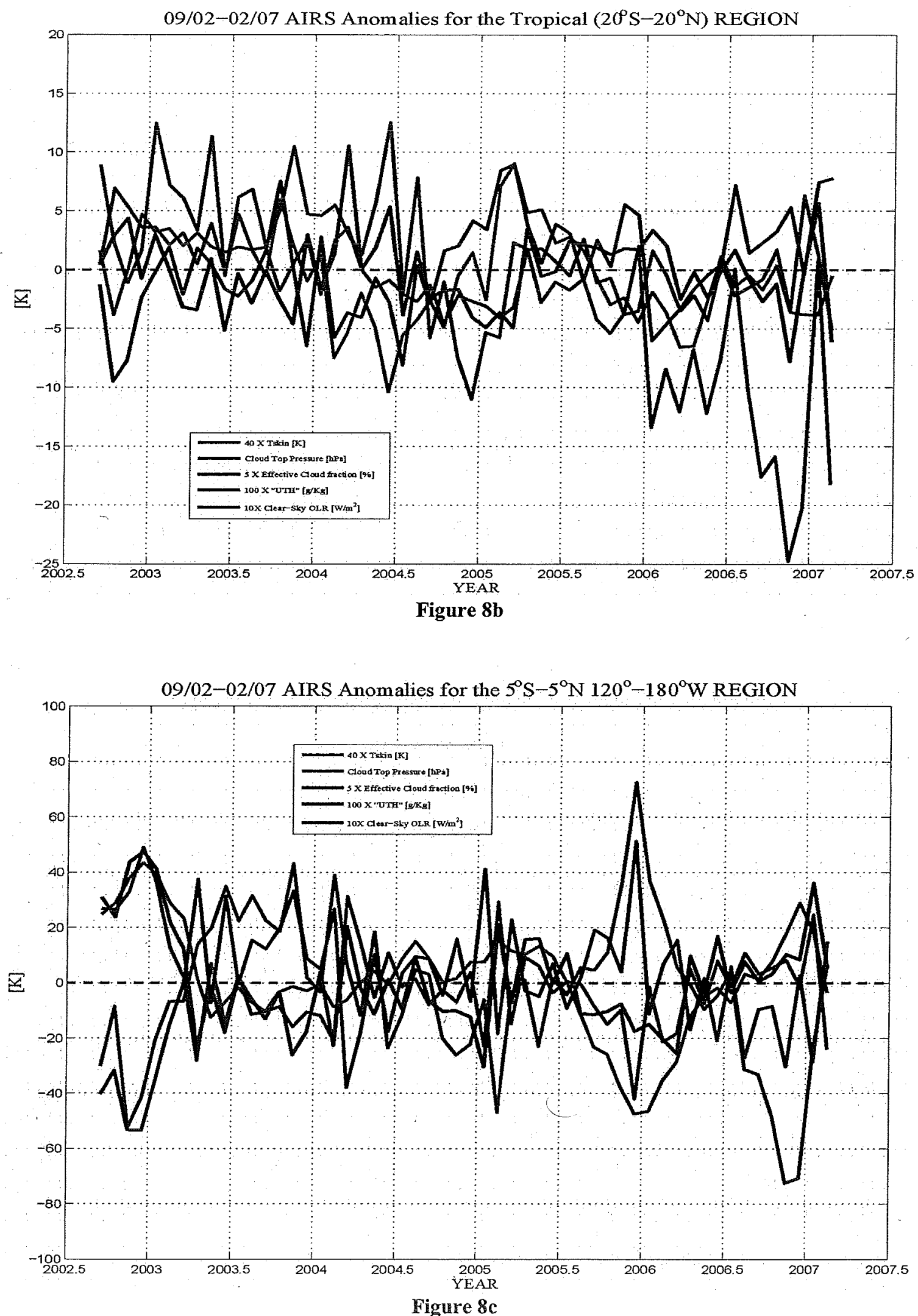


\section{SUMMARY}

The AIRS Version 4.0 monthly mean and 8-day average products as well as their temporal and spatial anomalies show reasonable consistency with each other and with other satellite products. Spatial and temporal interdependencies and correlations are also well represented by the (so far 4.5 yrs-long) AIRS Version 4.0 monthly and 8-day gridded retrievals. Version 5.0 (see Joel SUSSKIND's paper elsewhere in this issue), which DAAC will start processing before the middle of 2007, offers even better AIRS retrieval results for long-term assessments. Version 5.0 (and the future Version 6.0) will be even more useful for climate purposes because the spatial coverage of the Version 5.0 level 2 products (from which the level 3 products introduced here were created) is better. It is also independent of the microwave retrievals to a large extent and has additional products like all-sky OLR and Coarse Climate Indicators.

Nevertheless, even this preliminary evaluation Version 4.0 retrievals provides several "climatic" insights. For example:

- The change of the global mean temperature profile over the first 4 years of AIRS operation is fully consistent with GCM predictions for greenhouse warming as well as with independent measurements: surface and lower tropospheric warming and mid- and upper-tropospheric as well as stratospheric cooling. Meanwhile, in the Tropics, surface and upper tropospheric warming as well as mid-tropospheric and stratospheric cooling are observed, as expected. However, the magnitudes appear to be too large.

- On the other hand, the water vapor feedback, computed by models to enhance the greenhouse gas increaseinduced greenhouse warming by about $60 \%$, may not be operating as predicted. In fact, these admittedly shortterm AIRS data analyses show that on the global scale, surface skin temperature and UTH exhibit a (week) negative correlation instead of the expected strong positive correlation. Of course, even if this finding remains to be robust, it would just mean that the greenhouse warming will be closer to the lower limit of the predicted range than to the upper one, i. e., we still have to worry about it.

- Of course, these considerations are still preliminary, so we are planning to extend the scope of these initial assessments, including comparative validation studies using other, independent atmospheric parameter measurements.

- Obviously, to assess such climatic questions more reliably, the effects of potential instrumental drifts have to be severely limited, for example. We also need to compile the longest possible satellite sounder-based climatology, so we are also working on its backward extension, by integrating it with the other sounder-based climate dataset, namely the TOVS Pathfinder "Path-A" retrievals, available from 1979 through 2004. We hope that the AIRS-based dataset will complement/continue these satellite-sounder-based climatologies well into the future.

\section{REFERENCES}

1. Mehta, A., and J. Susskind, Outgoing Longwave Radiation from the TOVS Pathfinder Path A Data Set, $J$. Geophys. Res., 104, NO. D10, 12193-12212, 1999.

2. Susskind, J., P. Piraino, L. Rokke, L. Iredell, and A. Mehta, Characteristics of the TOVS Pathfinder Path A Dataset. Bull. Am. Met Soc., 78, 1449-1472, 1997.

3. Susskind, J., C. D. Barnet, and J. M. Blaisdell, Retrieval of Atmospheric and Surface Parameters from AIRS/AMSU/HSB Data in the Presence of Clouds. IEEE Trans. Geosci. Remote Sensing, 41, 390-409, February 2003. 
4. Susskind J., C. D. Barnet, J. M. Blaisdell, L. Iredell, F. Keita, L. Kouvaris, G. Molnar, and M. Chahine, Accuracy of Geophysical Parameters Derived from AIRS/AMSU as a Function of Fractional Cloud Cover, accepted by $J$. Geophy. Res. ,111(D9), doi:10.1029/2005JD006272, 2006.

5. Lindzen, R. S., Some Coolness about Global Warming. Bull. Am. Met Soc., 71, 288-299, 1990.

6. Molnar, G., and J. Susskind, Validation of AIRS/AMSU cloud retrievals using MODIS cloud analyses, Proceedings of SPIE, Vol. 5806, 618-629, 2005.

7. McClain, E.P. et al., Comparative performance of AVHRR-based multi-channel sea surface temperatures; $J$. Geophys. Res. 90, 11,587, 1985. 